\title{
INTRODUCTION
}

\section{What Is Happening to Epistemology?}

Christina Toren and João de Pina-Cabral

\begin{abstract}
Anthropologists debate the primacy of epistemology over ontology, and vice versa, or whether the one is bound always to implicate the other. Our collective and personal history, however, makes the lived world what it is for us, and not all explicit knowledge is constituted in the same way, with the same purposes in mind and within the same sets of binding parameters. Thus, the task of ethnography is to inquire into the different nature of the different forms and modes of constituting knowledge, even while we strive to understand what our own histories make us take for granted as self-evident. This article argues that as a profoundly radical endeavor after knowledge, ethnography goes to the very roots of inquiry into what it is to be human and thus provides for anthropology as a continuing comparative project of fundamental importance to the human sciences.
\end{abstract}

Keywords: analytical categories, epistemology, ethnography, history, human sciences, ontology

In proposing a discussion of 'an epistemology for anthropology', the editors intended a provocation, a challenge. Knowing all too well what comes of 'definitive solutions' to scientific problems, we did not seek to reach a consensus. Rather, given the contemporary focus in cultural studies and anthropology on ethnographic studies of scientific practice, attempts in cognitive science to build biologically and anthropologically valid models of mind, and new ethnographic endeavors to attain phenomenological validity, we wanted to explore the limits of current debate by bringing together views that clashed and subdisciplinary perspectives that diverged.

Challenged to consider what might be the primary condition for anthropological knowledge, certain of us were concerned with how we are to come to grips with what might be understood as changing conditions of theory building, for no one can deny that broader changes in the world at large have had an impact on the development of anthropological knowledge. ${ }^{1}$ Most of us, 
however, found our inspiration in ethnography, which is again unsurprising, for the ethnographic encounter has had a profound impact on the production of new ways of understanding what it is to be human. As will become evident in what follows, however, ethnography-as-inspiration takes different-even radically different-forms. For certain of our contributors, the writing of ethnography and theory building are mutually implicated aspects of one and the same activity, while others take ethnography to provide the basis for anthropological generalization. Certainly, the anthropological endeavor cannot be entirely comprehended by ethnography, but it is most decidedly marked by its principal analytical practice. So let us begin by asking, what do ethnographers want? The answers to this question inform what follows.

As ethnographers, we aim at phenomenological validity, such that our analyses can provide a way to understand any mode of human being-in-the-world, irrespective of whether the researcher is working with texts and archives that provide the material for a historical ontogeny of ideas or with rural Fijians in island villages, financial analysts in Paris and New York, social scientists in China, white working-class people in London, Tupinambá people in Brazil, or cosmopolitan intellectuals in Vietnam. The phenomenological validity of any ethnography rests on the human encounter between researcher and researched and cannot help but be based in the similarity that emerges out of our differences from one another, and the difference that resides in our similarities. We want to see a more general awareness that analyzing ethnographically the lived world of those closest to us (including ourselves) is just as tall (but no taller) an order as analyzing and understanding those distant others who seem most exotic to us. In no case is the relationship between researcher and researched to be taken for granted-not for reasons of an assumed mismatch of power that is bound to work in favor of the analyst, but because what is at stake here is the very possibility (or not) of an engagement with other human beings, whoever they may be, for the purpose of grasping the existential multiplicity of the human condition. ${ }^{2}$

We want an acknowledgment throughout the discipline of the necessity for an engagement with 'what it is to know' (epistemology) and 'what exists' (ontology), which themselves want finding out, with respect not only to others but also to ourselves, since the analyst's tendency is to take so very, very much for granted. This taking for granted has everything to do with the fact that, apart from studies of scientific practice, there is little ethnography concerning either our own processes of knowing (often held to be the province of psychology) or what exists for us (Western ontology is usually left to philosophers, and too rarely do anthropologists question the set of entities presupposed by the theories they use). ${ }^{3}$

Clearly, too, the human encounter that informs our ethnographies is not to be read in individualist terms (an ethnographer, an informant) because, in bringing these persons together, it entails acknowledgment of their lived histories and the social worlds in which they participate in face of an activity that aims at being mutually valid (phenomenologically valid). The mutuality of this human encounter is localized and particular but ultimately is to be understood 
in universal terms as a function of the similarities that reside in our differences from one another. This is where the focused analysis of life-as-lived by particular human beings with particular histories in particular places (ethnography) meets the comparative analytical project of understanding what it is to be human (anthropology).

Finally, we want a means for making other human scientists (neuroscientists, for example, or economists) understand that explaining the human condition requires that they (and we all) come to grips with the historicity that makes them and us-just like everyone else-accept the nature of our own lived world to be fundamentally self-evident. At the same time, we take note of Henrietta Moore's call (this issue) to heed the importance of self-questioning: "Languages of self-description are necessarily meta-languages, requiring a certain distance from experience ... They are not simply private and conceptual but are addressed to others, and as such they circulate publicly and are subject to contestation, recontextualization, and reinterpretation, providing a link between moral evaluations and actions in the world." In other words, they are "forms of objectification" bound up in processes of self-reflection that are inherent in all forms of action.

Given these considerations, what are the implications of undertaking ethnography for what we anthropologists know? In what ways does anthropology inform ethnography, and how does the latter shape future anthropological debates and ethnographic modes? Should we be concerned that some, considering anthropology too large a task, have fled the field to embrace cultural or area studies? That others have retreated into hermeneutic particularism, holding fast to a disembodied culture as the key to all knowledge? That yet others have espoused a cognitivism that makes neuroscientific models of brain function the measure of humankind everywhere?

We met in Lisbon in September 2007 at the Institute of Social Sciences, with the financial help of the Wenner-Gren Foundation and the Portuguese Foundation for Science and Technology. It will come as no surprise that during the three days of our meeting we often disagreed with one another, each participant being wedded to his or her own hard-won theoretical position and usually reluctant to give any ground. From the perspective of the editors of this issue, this was not a bad thing. So often in the past, shyness at engaging openly in theoretical debate has left anthropologists at the mercy of backward and unsophisticated stereotypes concerning our main mode of data gathering (participant observation), our primary form of analysis (ethnography), and our principal process of concept building (anthropological theorizing). ${ }^{4}$

The challenge we posed initially to our contributors gave rise to twelve quite different responses, whose relation to one another is, as will become evident, in certain respects kaleidoscopic. Each article bears on the nature of the anthropological project (broadly conceived), so even where one analytical position implicitly or explicitly challenges another, each article has a relation to and reflects elements of the others. With each new turn of the authorial lens, adjacent patterns are broken up and reassembled, producing a new and sometimes surprising order. Thus, what we find here is a kind of unity-in-diversity 
that demonstrates the sheer importance both of radical ethnographic endeavor and of anthropology as a distinctive discipline.

\section{Finding Out What It Is to Be Human}

Common to all is the continuing commitment to understand genuinely what it is to be human in all its multiplicity and, in so doing, to find out and explain in its fullness human being in the world. We are all aware of the vastness (even the impossibility) of the task, but we believe that it is profoundly important to keep at it, to struggle with what it means to study our fellow human beings (and through them, ourselves), to acknowledge all the messily manifest, historically specific entailments (at once philosophical, political and personal, conscious and unconscious) that emerge as inherent in the endeavor, and still to keep on.

The twelve articles collected here differ more or less greatly about what is meant by 'epistemology' and by 'ontology', and which of these is the central issue that should concern us. For Christina Toren, however, this problem is more apparent than real, a function of the analytical process itself in which, of necessity, certain issues are brought to the fore against a background whose character may remain implicit. She argues that epistemology and ontology always implicate one another and are best understood, therefore, in terms of a figure-ground relation. When epistemology is the figure, it can seem that too great an emphasis is being placed on processes that we seem largely, but by no means entirely, to have in common (how we know what we know) and that the ground (what the world is for us as particular human beings with particular histories) is being ignored. By the same token, when ontology is the figure, it can appear that the analyst is arguing for an idea of human being where un/consciousness can have no real purchase on the world and we are forever condemned to mutual incomprehension because the ground (here, how we know what we know) is left unexamined. The trick, then, is to hold onto the awareness that what exists for us and how we know what we know are, for any one of us, lived as inextricable from one another. ${ }^{5}$

Be that as it may, all of us are confident that we can find things out, and that what we find out can provide illuminating, if partial, answers to questions whose salience, whose very ontological foundation, emerges out of ethnographic analysis. Indeed, this is the heart and continuing strength of anthropology, for it is the only human science whose methods themselves engage the researcher directly in epistemological issues. ${ }^{6}$ Often enough, too, ethnographic analysis leads the anthropologist to examine critically the presuppositions concerning what exists for us that underlie his or her own methodological practice. It follows that for all the contributors to this issue, in one way or another, one of the central aspects of anthropology as explanation (or, we dare say, as science) is to find out what human being is for the people with whom we work, what the salient questions are for them, and what answers they themselves provide.

The concept of 'the people' (Scots, for example, or Cubans) is not to be taken for granted. Experienced ethnographers are plainly conscious that this is a methodological construct that they build out of their research material 
concerning human subjects who are never (and cannot be) a completely coherent collectivity. The very concept of the collective in its various forms is an anthropological device elaborated by modernist anthropology in order to allow for ethnography as a method of inquiry. In questioning the ontological status of such an idea, contemporary anthropological critique of sociocentrism takes a meta-linguistic position concerning the central presuppositions that grounded most of twentieth-century social scientific thought. Here, too, anthropology, because of its grounding in ethnography, can have a centrally creative role in the contemporary theoretical scene.

The very idea, however, that other peoples' ideas of human being and sociality have the same order of reality as our own, that their questions are as important and their answers as valid as those posed and answered by scientists (by economists and neuroscientists, for example, as well as anthropologists) is a difficult one to get across to those who hold that human reason finds its most perfect form in that specific kind of scientific rationality that insists on the necessity of setting up hypotheses and attempting to falsify them. ${ }^{7}$ Indeed, it is difficult for anyone to grant credibility to ideas about what exists for us and how we know what we know that differ to any profound degree from their own. So many of us today-inside as well as outside the human sciences-still fail to understand that the specific nature of scientific knowledge is such that no lifeworld can be built on its basis. The days in which utopian thinkers believed that they could build a rational life-world (one that would be compatible with modes of everyday experience) appear not to have entirely passed away, however, even though scientific socialism is no longer the order of the day.

Sociality is a fundamental condition of human being, and the particular forms that sociality takes are a function of intersubjectivity, which is always and necessarily prior historically and, by the same token, developmentally. We humans have the peopled world in common, and intersubjectivity is always antecedent, but-and this is a big but-each of us lives the world as a function of his or her unique history, whose parameters each of us projects into the world with some confidence that we are right, only to come up against those of other people-our spouses, our children, our neighbors, our informants in the field who often enough become our friends-and discover differences that we may perhaps reject out of hand or strive to understand, depending on our stance toward the other. This is an aspect of the human condition: to assume sameness in others (whether considered collectively or as particular persons) and discover difference; to assume difference and discover sameness. It is the basic disposition that Donald Davidson (2001) calls the principle of interpretive charity, and it underlies all forms of human communication (see Pina-Cabral below). How we respond to it has everything to do with our own past histories and hence with our disposition to grant to others the same humanity (intelligence, perspicacity, passions, insight, depth of feeling, and so on) that we grant to ourselves, even while we have to realize that we may not be able to grasp fully the specific forms that their humanity takes.

It follows that doing anthropology in one's native country-'down the road' in Bahia (Brazil) or in the Scottish Highlands-poses problems of the same 
magnitude as doing anthropology far away from one's own place in Fiji, Papua New Guinea, Cuba, or Kenya. Even so, not all explicit knowledge is constituted in the same way, with the same purposes in mind, and within the same sets of binding parameters. It is an ethnographic task to inquire into the different nature of the different forms and modes of constituting knowledge (and that, of course, includes the practice of science).

In response to a searching ethnographic question from Daimã, a Yudja woman from the Xingú River in central Brazil, Peter Gow shows how, when the analyst turns the ethnographic endeavor on himself and his ancestors, an investigation of the ontogeny of ideas reveals that "common and scientific observation are the same thing." Gow's analysis finds its focus in an effort to understand the implications for his own ancestors (and for himself) of Scottish Enlightenment thinkers' specifically scientific concern: "Rather than being pursued for its own sake, reason was to be applied to the world and to the improvement of human life." One such thinker was James Hutton, whose Theory of the Earth "invented geology as a by-product of thinking about how landowners could improve the soil of their properties." Gow's analysis shows how standard agricultural practices were represented as irrational and how the Highland Clearances used this representation to justify the introduction of sheep farming. The Clearances at once treated as irrelevant the common people's knowledge of duthchas, which involved "hereditary right of access to specific parcels of land," and increased the rental value of land to which a titled landowner might hold the written title deeds. This ethnographic analysis of an ontogeny of related ideas is able to show that Adam Smith's profoundly influential idea of 'the four stages of society' was derived "directly from the transforming spatial forms of Scottish life." Gow's compelling analysis provides an answer to Daimã's question about what makes him the kind of human being he is, reveals new dimensions of the lived political economy of a brutal aspect of our intellectual history as anthropologists and human scientists, and manifests tellingly his view that anthropology has no need of any epistemology other than ethnography.

For all our contributors, the effort to find out and explain others entails an investigation of who they are themselves and how their own ideas and practices inform their fieldwork and their ethnographic analyses-indeed, this is one of the main methodological traditions that have emerged out of contemporary anthropological debate. Except where it is particularly germane to the material under discussion (as above), this self-investigation remains implicit, as do, often enough, aspects of the contributors' theoretical commitments. Jadran Mimica takes perhaps the most radical view of the ethnographic endeavor, making it the ethnographer's task to understand fully that his or her "character and personality structure are both the limiting and facilitating conditions of the ethnographic project itself," which entails a genuine self-critical exercise in reflection, as opposed to the "idealized self-representations ... in so many would-be self-reflexive ethnographies.” Real ethnographic knowledge and theoretical understanding demand "endless concrete work, a permanent self-modification that can be characterized as an intra-psychic surgery by one's own hand." This is because "[a]n ethnographer neither lives the life nor dies the death of 
the people s/he is working with ... it is the interrelations between the two and the dynamics of human passions and radical imagination that constitute the ontological nexus of any given life-world." For Mimica, the life-world of the Yagwoia of Papua New Guinea, with whom he has worked for 30 years, is, just as it is for all of us, "the life-made-culture, made so by the plenitude of desires of the human embodied un/conscious psyche, whose primordial project is its own self-projection into and actualization as phantasy-which-is-the-world." Thus, his own work resides in the continuing endeavor to grasp this particular constellation of Papua New Guinean subjectivity and its life-world. Here he gives us an ethnographic insight into what it would be to live an "oneiric mode of experience, [which] makes it clear that, for the Yagwoia, their life-world is no less real in their dreaming than in their wakefulness." In so doing, Mimica invokes Castoriadis's "radical imaginary" as "literally, the ontological source of all human reality ... the creative matrix by virtue of which there is any given human cultural life-world." Mimica's ethnographic-cum-psychoanalytic account is phenomenologically grounded in the Yagwoia life-world such that it at once "maintains and amplifies [its] ontological originality and existential integrity."

\section{Questioning How We Know What We Know}

Given that subjectivity is always and inevitably a function of intersubjectivity, any and every subject-object engagement with the world is historical through and through. Our present endeavor to interrogate the grounds of knowledge for our own discipline is a case in point. In short, none of us can escape his or her history, but we can strive to engage in good faith with others and, in so doing, grant constitutive power to their collective and personal histories and to our own. The struggle, then, is truly to understand others without merely assimilating them to our own ideas.

It follows that this desideratum is itself historically grounded. Throughout the twentieth century, the idea of cultural difference evolved, and even to this day it has not freed itself totally from conceptions of progress and cultural development (which are, in the long run, tantamount to assimilation). This principal guideline of contemporary ethnography is being taught all over the world to anyone who learns anthropology. Specifically, it emerged as a global human project in the twentieth century in the wake of the globalization of modernity. Of all the sciences, anthropology was a major player in this process, having made an extensive effort to free itself from Eurocentrism. In order to see how this might be the case, we have to question the stereotypical unitary view of modernity, which continues to associate modernness with the West, and to adopt instead a pluralist notion (cf. Pina-Cabral 2005: 121-125). ${ }^{8}$ The contribution to this issue by Filipe Carreira da Silva and Mónica Brito Vieira-looking at anthropology from the outside, as it were-is especially valid in this respect.

Of course, we want to bring home to other researchers in our own and other disciplines the continuing, even increasing, necessity to engage with ethnographic findings and anthropological abstractions in an age when it appears that for so 
many theorists the globalizing effects of capitalism tend to push all other considerations out of the way. How we are to do this, however, is a matter of some contention. For Carreira da Silva and Brito Vieira there is no sense in looking for "universal epistemological foundations, a search that is associated with the quasi-naturalistic agenda of liberal rationalism." Instead, the way forward is to engage in the "transdisciplinary flow between disciplines, methods, and theories that characterizes the cutting edge of science today." They see the best solution as an engagement in "dialogical pluralism," that is, "a meta-theoretical strategy that sees the history of theory and theory building as different sides of the same coin." As an example of dialogical pluralism in science, they discuss Honneth's critical response (using Hegel and G. H. Mead) to the task of understanding "the inner logic of the concrete forms that human conflict assumes in different social spheres, from the private/intimate domain to the realm of work relations." They emphasize "the need to complement a historically minded reconstruction of our predecessors with a theoretically sustained examination of the inescapable questions they sought to answer." Along the way, they provide us with a useful analysis of “[a] plural modernity, with several historically entangled varieties.' Their analysis meets the central concerns of most of the participants in this debate when, in the wake of Wittgenstein, they call for the central theoretical importance of making sure that "the 'thick' fabric of culture, sociality, and history does not 'go on holiday'." They claim that a contemporary preoccupation with theme-driven and problem-oriented research, which promotes a transdisciplinary mode of scientific production, is not incompatible and is, in fact, dependent on disciplinary forms of scientific reproduction. This historicist approach to scientific work, too, was largely consensual among our contributors.

Taking a quite different tack, Martin Holbraad sees a concern with how we know what we know as itself fundamentally wrong-headed, as inevitably bringing in its train "the epistemological assumption that truth must be a property of representations that make claims about the world" and thus logically entail the possibility of falsification. He argues that "the most distinctive characteristic of anthropological thought .... [is that] it is oriented toward difference" and that " $[\mathrm{t}]$ he questions that alterity poses to us anthropologists pertain to what exists rather than what can be known." He wants us at once to retain a hard distinction between ontology and epistemology and to recognize that "since anthropology is centrally concerned with alterity ... anthropology must reflect upon its modus operandi in ontological rather than epistemological terms." This entails the recognition that "some data resist collection ... because the concepts available to anthropologists for describing them are inadequate." By means of an examination of Cuban Ifá divination, in which the role of truth "is not to make a claim about the world but rather to change it-to interfere ... in its ontological constitution," Holbraad argues that anthropologists need a different concept of truth as "inventive definition." This idea of truth does not entail falsification as its opposite, precisely because "it emerged as an answer" to the kind of question that asks how far we, as anthropologists and analysts, "have to change our assumptions about what counts as truth before we could say that oracles give truth." Holbraad asks us to start with the assumption that 
“anthropology is not about 'how we think they think'. It is about how we could learn to think, given what they say and do."

Beginning with Roy Wagner's observation that "every understanding of another culture is an experiment with our own," Tony Crook shows us how very enlightening ethnography can be when it takes seriously the relations between the researcher and those with whom he or she works-that is to say, when it does not pretend to screen out "the 'bodily-personal-relational' from the 'social science' by means of methods." Crook uses his work with the Min in Bolivip, Papua New Guinea, to show how Barth's ideas about Baktaman 'secrecy' were dependent on anthropology's own “field research metaphors of uncovering data, revealing connections, and entering initially opaque new cultural worlds in search of hidden meanings." For the Min, knowledge is 'skin' — substantial-and coming to know something is 'making skin'; here "knowledge always comes of and from someone, and never goes about on its own as if alienated as some kind of object or detached from the people who hold it." It follows that while people in general (and senior men in particular) attest to the necessity for secrecy and the danger of certain knowledge to the uninitiated (women, for example), secrecy cannot be all or nothing. Rather, as one man told Crook, "knowledge of important things can be given to those who have felt sorrow, who have looked after and respected them, provided that they hide it so that no one knows." Thus, men tell important knowledge to those particular women who respect and care for them and who, for this very reason, need to know what is required of initiated men. Moreover, it is evident to people-and discussed-that solving a problem or finding something out adumbrates a ground from which it springs, whose substance and extent is as yet unknown. As Crook explains: "For every time something is disclosed and becomes clear, people immediately perceive that it has revealed alongside it something else that remains hidden."

There are lessons here for us as anthropologists and as human beings. When we address one another as researchers and scholars engaged in the same task, immediately we encounter and make much of those differences in analytical vocabulary whose theoretical entailments we hold to compromise our effort toward understanding. This makes sense to us and is justified in part because it is indeed the case that our analytical categories set the parameters for our explanations, and in part because our own passions are engaged in what we do. What counts in the end, however, is what our ethnographies can bring to our anthropological understanding of what it is to be human. The anthropological endeavor is as profoundly important and urgent today as it has ever been.

\section{Reclaiming Ethnography}

By means of an ethnographic re-examination of so-called fetishism in the AfroBrazilian religion candomblé, Marcio Goldman argues that there is no need to give pre-eminence either to epistemology or to ontology. In candomblé, the 
creative process that 'makes the saint' or 'makes the head' consists in finding in an object or person what cries out to be found and made-brought into being, as it were-because it is already there. This is a beautiful ethnographic demonstration of why particular manifestations of how we know what we know and what exists for us may be understood as aspects of one another. The fused possibilities thus provided for make it plain that being and becoming are likewise, that all the environing world of people and things (including ourselves and everything that we know) goes on and on, becoming what it already is-from which it follows that potential manifold possibilities are already there to be found out and actualized in a world in which "nothing is lacking." Goldman's analysis of candomblé exemplifies his implicit axiom that anthropologists should be using only the epistemologies and ontologies offered by the people with whom we work.

Christina Toren agrees with this view, even while she sees the primary difficulty for anthropologists as a particularly powerful case of the problem we have in our daily lives. If we are genuinely to credit other people's understandings of the world (what they take to exist or what might come to be as a function of how they know what they know), we have also to recognize, first, that the environing world provides for all the meanings that humans can make and, second, that our own understandings are no less amenable to historical analysis-that is, no less explicable by social analysis-than the next person's. It follows that because our own categories are of only limited use in understanding other people's, since they are at best initial approximations, the explanatory power of our ethnographies must reside in rendering our informants' categories analytical. Toren's article is an ethnographic argument for a model of human being and for ontogeny as a historical process that provides at once "for the analysis of social relations and for how they inform the constitution of meaning over time by particular persons in such a way as to produce meanings that are always unique ... even while they are always recognizable for what they have in common with meanings made by others." She argues that this model entails an ethnographic analysis that, when turned on ourselves, is bound to reveal aspects of our own understanding of what the world is for us, and how we know it, to which we would not otherwise have access. ${ }^{10}$

Susana de Matos Viegas argues in favor of a style of anthropological generalization that arises out of ethnographic experience. For her, generalizing can be based on an evaluation of diversity and need not require a postulation of uniformity. It is bound to be founded in processes that bring together ethnographic intersubjectivity with comparative abstraction. Her ethnographic demonstration of how, for the Tupinambá of Brazil, 'places' are at the very heart of sociality, kinship, and history first required long-term participant observer fieldwork. An understanding of intersubjectivity was at the heart of Viegas's initial close analysis of daily life in the small locality of Sapucaeira. Some five years later, this was followed, at the behest of the Brazilian government, by an extensive two-month survey of residential arrangements among Tupinambá throughout the region of Olivença. It was this study that enabled Viegas to generalize her findings and to argue convincingly against the idea that the Tupinambá people on the Atlantic 
Coast had 'disappeared'. For even while acknowledging the diversity of existing arrangements and the fact of historical processes of expropriation of land, she was able to show how an "ethnography of the Tupinambá's lived experience in lugares provides us ... with a different picture" of contemporary diversity and its history. The powerful conclusion of Viegas's article makes it plain that the "epistemological tools that allow us to reach valid generalizations correspond simply to the axis of anthropological training."

Toren has long argued that we have to be thoroughgoing in doing away with what Holbraad sees as "the dilemma between universalism and relativism ... [which entails] that mainstream anthropological thinking relies on a remarkably uniform image of what counts as anthropological truth." For Toren, the solution lies, however, not in a redefinition of what constitutes truth, but in rethinking our models of human being such as to have as our focus a phenomenon that is through and through at once historical and material (see Toren 2002). It follows that the biological and the social, mind and body, the material and the ideal, subject and object, the relative and the universal, epistemology and ontology (and so on and so on) are in each case best understood not as separable and dialectically related analytical entities but as aspects of one another, like the two sides of the continuous surface that is a Moebius strip. In this view, the anthropologist's task is to show not only how all our ideas and practices (including his or her own) constitute the transforming world, but also how the fullness of the world is such that it is capable of confirming all our ideas of it, even while, often enough, we may question whether indeed we are right.

What constitutes confirmation for us is itself an artifact of our lived histories. The confirmation of a drug's efficacy that is required by a double-blind experiment differs from the confirmation that is discovered through the use of a herbal remedy when the placebo effect is not ruled out. And they both diverge markedly from the confirmation of a suspicion that ensues when new information comes to light about 'what was really going on' when a certain political deal was arrived at, or from our projections onto another person in which we find confirmation in their every action of our own ideas of their moral worth.

Science shares its history with all human thought, but, as Pina-Cabral reminds us, in the same way as there is no single theoretical foundation that will remain forever stable, there is no stable empirical base for it all. Ethnographic generalization alone would never have invented anthropology-that is ultimately an empiricist dream, and it can be contemplated only if we believe that one could have anthropology, historically, without having had earlier on an idea of science and an institutional investment in the production of science. Similarly, anthropological theory would be blind without ethnography.

At the same time, as we all recognize-and as Gow's article so cogently demonstrates-our scientific thought is enmeshed in certain forms of political economy along with all our other ideas. Indeed, the hierarchy of sciences can be argued to have more to do with the technologies of control that they make possible than with the breadth and quality of the knowledge that they produce. It is instructive to note, for example, how biology has become very much a 'hard science' (rivaling even physics) since the dream of controlling the 
human genome appeared on the horizon of possibility. Science as a mode of understanding the world is a particular human project, yet the kind of validity it produces cannot rule out other forms of validity that are not founded in scientific premises. Nor can science encompass what ultimately escapes control: the extraordinary fecundity of mind. From conception onwards, each of us is the autopoietic (self-creating) product of our transforming, intersubjective engagement in the environing world, whose lived contingencies may produce new, unlooked-for trajectories of existence. The fact that this process is in its very nature historical explains why the lived world of people and things is always co-extensive with the subject.

Considered as an epistemology and entailed ontology (or vice versa), this view at least has the virtue of realizing that we cannot help but project into the world those aspects of ontology that our own particular history makes salient to us and find them confirmed. That this is as true for the anthropologist as scientist as it is for his or her informants does not (and cannot) rule out the possibility of disconfirmation for either, for after all, as is plain in Pina-Cabral's reminder concerning the "all-or-nothing syndrome," the possibility of disconfirmation inheres in all knowledge processes (although of course this possibility may be denied or taken to be irrelevant). Moreover, however hard we try, we cannot make any given other, however close, think quite as we do-and this applies as well for those who feel sure that they agree with us.

The understanding of human autopoiesis as always and inevitably a historical process, Toren argues, allows for a more profound investigation and understanding of the multiplicity of what it is to be human than does the idea that there is a universal biological substrate upon which culture imposes itself in diverse and usually erroneous forms. That culture is nowadays held to manifest itself in ever more highly differentiated microforms that provide for distinctions between, say, the culture of one multinational corporation and that of another has not done away with the crude distinction between biology and culture. This is still with us, for all it is fudged by those who argue that human capacities that provide for a universal rational propensity can be isolated, as it were, from other human capacities whose artifact is social or cultural. This idea has recently gained new strength in the cognitivist paradigm that attempts to put paid to the core idea of anthropology that it is profoundly important for the human sciences to recognize that we humans, considered collectively or as particular persons, really can-and really do-live the peopled world differently from one another and find our ideas of it by and large confirmed. Thus, one of our continuing problems as anthropologists is to explain phenomena that we may think we already understand because, at least historically, they pertain to ourselves.

\section{Having It at Least Partially Right}

The persuasive analytical power of ethnography resides, in one way or another, in its demonstrable purchase on the lived world. João de Pina-Cabral argues that "there is no possible description of what actually occurs in the ethnographic 
encounter that does not presume some form of realism." This is not, however, an argument for positivism. Inspired by the work of Hannah Arendt and of the analytical philosopher Donald Davidson, Pina-Cabral asks us to accept that an acknowledgment of human historicity does not imply that there is no truth: "[H]istoricism runs counter to truth only [if we] confuse the existence of difference [between humans] with the absence of relevant similarity." Thus, he calls for a renewed engagement with the concept of the human condition as a precondition for anthropological thinking. This will necessarily involve a new approach to anthropology/ethnography as scientific practice.

The project of understanding what it is to be human, in other words of anthropology as science, is not and cannot be all or nothing. Pina-Cabral argues for an abandonment of the framework that presumes that we might have access to total truth. It is this kind of utopian disposition that gives rise, in the face of failure, to postmodern despondency. He calls our attention to what Davidson (2001) has described as "the fallacy of reasoning from the fact that there is nothing we might not be wrong about to the conclusion that we might be wrong about everything" (ibid.: 45). We should reject positivist notions of anthropology quite as much as contemporary, discourse-ridden dystopias. In this way, Davidson's argument meets up with the debates concerning modernity developed by Carreira da Silva and Brito Vieira.

To the contrary, Pina-Cabral argues, the anthropological endeavor has to be rooted in the awareness that it is proper to the human condition that human actions are irreversible, unpredictable, indeterminate, and underdetermined. It is precisely this recognition that makes for the "possibility of getting things at least partially right." Moreover, "[t]hese are not variables that apply solely to ethnography/anthropology; rather, they apply to all action and to all interpretation." "Anthropologists-as-ethnographers, as much as anthropologistsas-theorists," Pina-Cabral claims, are especially well positioned to understand that "we would never have been able to reach any knowledge concerning the world's plurality if we had been stuck in a solipsistic universe."

Certainly, we want to be able to capture the multiplicity of what it is to be human, but for Pina-Cabral there are serious difficulties in rejecting too briskly the notion of a single ontology. One might safely argue that ethnography reveals a plurality of ontologies, but this should not lead one to deny the existence of a single world: methodological relativism must not be allowed to collapse into ontological relativism. If alterity and identity are seen as being symmetrical-which is characteristic of the sociocentric way in which anthropology thought itself out as 'the science of difference'-then it becomes possible to contemplate the existence of all sorts of parallel ontologies placed before each other unitarily, as it were, in a row. This posture, however, would amount to a form of essentialization of the human subject or of human 'groupness'-some sort of always-already-existent 'us' - which would be even worse. It would be a form of forgetting that we all arise out of a confrontation with an other.

It follows that alterity and identity should not be seen as symmetrical, for the very possibility of identification and differentiation sits historically on the existence of an earlier form of alterity that is the constitutive ground out of 
which arose all identity. The possibility of human autopoiesis depends on a foundational confrontation with an anterior other. If all human beings and all superpersonal forms of identity arise out of others, this means that there is ultimately only one world. Therefore, on the one hand, we are all socio-culturally situated-and indeterminacy rules-but, on the other hand, we all share a door of entry that opens up an escape route to the situatedness of our condition. This is the door of anterior alterity.

To that extent, we can all hope to be able ultimately to make at least some sense of each other, and we must therefore live in a world that, while not necessarily unitary, is common to us all. It could be argued that this is a form of monotheistic ideological fantasy that is characteristic of 'the West'. But a monotheistic ontology is not only single, it is also unitary (and fundamentally sociocentric), so the accusation is beside the point. It could further be argued that this has little relevance for anthropology, which, being based on ethnography, has little use for such ultimate forms of determination. Pina-Cabral believes that this is not the case, for the ethical implications of ontological relativism are so tremendous that they would question the very foundations of the anthropological enterprise.

In a similar vein, Andre Gingrich concludes in his article that now is "the right time to envision a comparative anthropology of epistemologies," with an emphasis on "non-monotheist epistemological and philosophical traditions that are not based upon one creator." He holds that we may achieve this in part by "strengthening phenomenological elements in socio-cultural anthropology's epistemological reorientation," in order explicitly to take into account the different epistemologies of the peoples with whom we work and, by implication, to make real analytical use of them. Gingrich is particularly concerned with making possible an interdisciplinary conversation in which the ethnographer uses the fine-grained ethnographic analysis derived from primary field data toward the formulation of "medium-range conceptualizations and empirically saturated hypotheses ... related to groups of cases that we might label 'mesoevidence'." This kind of evidence will enable a "new realism" that will broaden and reinvigorate the discipline and provide the means for us to address the human condition and the problems of a globalizing world.

This emphasis on the reality that manifests itself more or less differently in each and every one of us invokes the ground of what it is to be human to which we can never gain unmediated access. Thus, Yoshinobu Ota sees the major problem as being that of "how seriously one takes the nature of cultural mediation." He holds to a position derived from Boas that "reality as it appears to the people under investigation ... is constituted through imaginings" and that because this is also the case for us as analysts, "ethnography is thus the result of double mediation." He is sympathetic to Taussig's approach which, he says, "nullifies the line of contention between reality and imagining, since it denies the existence of reality independent of consciousness and, at the same time, affirms the realness of the world created by such imagining."

Ota's is a plea for an approach that takes full account of the fact that reality mediated through imagining or consciousness cannot be "wished away." Ota's fieldwork in Guatemala makes him think in terms of "the world infused with 
social relations," which, in informing how imagination functions to constitute the world, informs not only the "strange tales," whose truth Guatemalan villagers at times assert and at other times contest, but also the production and writing of ethnography. Ota asks us to accept that reality cannot be independent of consciousness, and all of us would accept that human consciousness, as manifested in ideas and practices, is constitutive of the reality of the worldas-lived, even if we also know that the world continually escapes (or challenges or throws into question) human understandings of it, to the point that we (especially, perhaps, we anthropologists) are continually questioning what reality might be.

Thus, Henrietta Moore asks us to face up squarely to "the epistemological challenges inherent in recognizing that the new forms of agency and subjectification that are arising in Africa will likely ... shape the future of the next stage of what we now term globalization and will also change the way that we think about and practice social science." She looks at what happens when "significant changes in culture and in ritual practices ... have been the result of intensive activity on the part of churches, local NGOs, and the government." Her study of Christian Marakwet girls' rejection of circumcision and their embrace of alternative rites of passage shows that when certain practices are reified such that they come to be considered explicitly as culture and as objects of knowledge, this very process makes way for "new forms of knowledge and their explicit link to enhanced agency." Moore contends that the "hyper-agency of radical Christian belief and ... the way individuals and their ideas about knowledge and action have become part of international Christian networks" make it impossible for us as anthropologists to follow the well-worn anthropological practice of rendering our informants' ideas "rational in context." Moore insists that we look at the researcher as well as the researched in an effort to understand "forms of self-description and self-objectification," so that we can attempt to meet the ethical and epistemological challenges that they present.

\section{Inspiring Anthropology}

The idea that ethnographic analysis is the primary condition for the development of anthropological knowledge is strongly asserted by 9 of our 13 contributors-most powerfully by Jadran Mimica, who argues that ethnography is best founded in an approach that marries phenomenology and psychoanalysis. The others take different theoretical perspectives and thus give a different expression to the inspiration of ethnography: for Gow, it provokes a question and suggests a means of answering; for Goldman, it is an axiom from which the analysis of other concepts can proceed; for Moore, anthropological understanding and interpretation are intimately tied to other people's local knowledge, a fact that has ethical as well as epistemological implications; for Holbraad, it is a standard from which ideas of truth can be critically assessed; for Ota, it supplies the element of surprise and wonder that is so crucial for the creation of new understandings; for Viegas, it is the key to showing how history gives rise to 
contemporary diversity; for Crook, it is the means for understanding epistemology as always concretely relational; for Toren, it enables the anthropologist to render analytical the categories of the people whose lived ideas and practices are the focus of study. Implicit here is an awareness that ethnography as science always has its source in an intuitive recognition of something human that at once defies understanding and demands it. The articles by our remaining four authors provide perspectives that both oppose and complement the ethnographic articles. Carreira da Silva and Brito Vieira want us to think about anthropological epistemology within the framework of a more general debate about the nature of modernity. The transformations in the institutional form of the academy and the state, they argue, call for a radical conceptual shift in the social science. In a related argument, Gingrich makes a plea for "new realism" and a comparative anthropology of epistemologies, while Pina-Cabral argues strongly for the scientific value of anthropological knowledge.

When we-that is, Toren and Pina-Cabral-questioned our colleagues about the epistemological conditions for anthropological knowledge, we did not expect consensus; indeed, we consciously worked at avoiding that outcome. Even so, the careful reader of this collection will see that we arrived at a kind of non-foundationalist consensus. Pina-Cabral, Ota, Gingrich, Carreira da Silva and Vieira Brito, Holbraad, and Moore are all primarily addressing long-vexed issues that they see as continuing to bedevil anthropological practice at large. They are by no means in agreement with one another as to where the answers might lie, but all are concerned with the clarity and theoretical utility of our analytical categories across disciplines and are very much alive to how good ethnography can make a real and much wanted difference to explanation in philosophy and the human sciences. The rest of us-Gow, Mimica, Crook, Goldman, Toren, and Viegas-are more inclined to push our own ethnographic analyses to their limits in an effort to demonstrate what kind of sense they can make. There is an absolute commitment here to ethnography as a profoundly radical endeavor toward achieving knowledge-one that, in going to the very roots of inquiry into what it is to be human, continues to manifest itself as inexhaustible and to constitute itself anew-and a commitment to anthropology as a comparative project that lies at the very heart of the possibility of understanding human being in the world.

\section{Acknowledgments}

Thanks are extended for the support and financial help of the Institute of Social Sciences, Lisbon, the Wenner-Gren Foundation, and the Portuguese Foundation for Science and Technology. Thanks to all those who participated in the original Lisbon workshop and the follow-up at the University of St Andrews. We are most grateful to all our contributors for the passion and seriousness that they brought to this project. Special thanks to two anonymous readers for Social Analysis, who will recognize where we have made use of their insights. 
Christina Toren is Professor of Social Anthropology at the University of St Andrews. Her regional interests lie in Fiji, Melanesia, and the Pacific, and her anthropological interests in theories of human being, kinship, ritual, and exchange processes. She is the author of numerous articles and two monographs, Making Sense of Hierarchy: Cognition as Social Process in Fiji (1990) and Mind, Materiality and History: Explorations in Fijian Ethnography (1999).

João de Pina-Cabral is Research Coordinator at the Institute of Social Sciences of the University of Lisbon, where he was Scientific Director from 1997-2003. He was Founding President of the Portuguese Association of Anthropology (1989-1991), President of the European Association of Social Anthropologists (2003-2005), and Malinowski Memorial Lecturer in 1992. He has carried out fieldwork and published extensively on the Alto Minho (Portugal), Macau (China), and Bahia (Brazil). He has been a Visiting Professor in the UK, US, Brazil, Spain, and Mozambique.

\section{Notes}

1. For a historical overview of anthropology and epistemology, see Moore and Sanders (2006).

2. Assessing the impact of the Sahlins-Obeyesekere debate, Kapferer (2000: 183) discusses certain characteristics of anthropology's self-critique. He characterizes anthropology as a "fractious discipline" and argues that "some (but by no means all) postmodern anthropological criticism has contributed both to destructive representations of much anthropological practice and ... to an unnecessary trivialisation of central concepts and methodological requirements for anthropology" (ibid.).

3. But see Edwards, Harvey, and Wade (2007), who bring together ethnographic studies that focus on "how particular objects of science came onto the agenda as significant, what other ideas they are surrounded by and how ideas travel and have effects in the world" (ibid.: 10).

4. Compare with concurring opinions as expressed by Richard Wilson (2004) and Borneman and Hammoudi (2009).

5. Toren's formulation addresses Viveiros de Castro's (1998: 479) concern that anthropologists "persist in thinking that in order to explain a non-Western ontology, we must derive it from (or reduce it to) an epistemology"; it also acknowledges the justice of Strathern's (2005: 42) observation about "the tool science has made of the duplex 'relation' ... Positivism and its critiques ... are both .... an outcome of scientific thinking insofar as they put 'knowledge' at the forefront of relational endeavour and can imagine different approaches to it."

6. See Bruce Kapferer's (2007) illuminating discussion of the need for conjoining the humanist and the scientific heritages of anthropology. In particular, note his definition of the discipline as "a rigorous knowledge practice, by and large non-positivist in orientation, that claims the knowledge it produces has a degree of validity which, like any scientific practice, is never beyond contestation or immune from radical doubt or scepticism" (ibid.: 78).

7. See Stafford (2008) for a comparison of the significance of falsification for psychology and anthropology. With respect to studies of numerical thought, he focuses on "how much cultural evidence psychologists are prepared to take on board, and ... to what extent anthropologists are prepared-or even able-to provide psychologists with the types of (stripped-down) evidence they want or need" (ibid.: S130).

8. In anthropology, this unitary view of modernity often enough takes the unpalatable form of paternalistic and self-righteous breast-beating. Compare with Bruce M. Knauft's (2002) introduction to his wide-ranging edited collection on alternative modernities; 
Knauft's call for us to rethink modernity includes a review of contributions by anthropologists. Compare with Aguilera Calderòn's (2008) ethnographic critique of the use of any idea of modernity to explain vodou practice in contemporary Benin.

9. The reference here is to Maurice Bloch's (1988) How We Think They Think.

10. With regard to how certain British children come to be who they are, Evans (2006) provides an exemplary ethnographic analysis of how the ideas of adults (parents and educationalists) structure the conditions under which these same children arrive at and make manifest their own rather different ideas of themselves and the world.

\section{References}

Aguilera Calderòn, Anna-Maija. 2008. "The Vodou Priest Who Lost His Spirit: Reflections on 'Modernity' and 'Tradition' in a Beninese Village.” Pp. 118-132 in How Do We Know? Evidence, Ethnography and the Making of Anthropological Knowledge, ed. Liana Chua, Casey High, and Timm Lau. Newcastle: Cambridge Scholars Publishing.

Bloch, Maurice. 1998. How We Think They Think: Anthropological Approaches to Cognition, Memory, and Literacy. Boulder, CO: Westview Press.

Borneman, Jon, and Abdellah Hammoudi. 2009. "The Fieldwork Encounter, Experience, and the Making of Truth: An Introduction.” Pp. 1-24 in Being There: The Fieldwork Encounter and the Making of Truth, ed. Jon Borneman and Abdellah Hammoudi. Berkeley: University of California Press.

Davidson, Donald. 2001. Subjective, Intersubjective, Objective. Oxford: Clarendon Press.

Edwards, Jeanette, Penny Harvey, and Peter Wade, eds. 2007. Anthropology and Science: Epistemologies in Practice. Oxford: Berg.

Evans, Gillian. 2006. Educational Failure and Working Class White Children in Britain. Basingstoke: Palgrave Macmillan.

Kapferer, Bruce. 2000. "Star Wars: About Anthropology, Culture and Globalisation." Australian Journal of Anthropology 11, no. 2: 174-198.

2007. "Anthropology and the Dialectic of Enlightenment: A Discourse on the Definition and Ideals of a Threatened Discipline." Australian Journal of Anthropology 18, no. 1: 72-94.

Knauft, Bruce M. 2002. "Critically Modern: An Introduction.” Pp. 1-54 in Critically Modern: Alternatives, Alterities, Anthropologies, ed. Bruce M. Knauft. Bloomington: Indiana University Press.

Moore, Henrietta L., and Todd Sanders. 2006. “Anthropology and Epistemology.” Pp. 1-21 in Anthropology in Theory: Issues in Epistemology, ed. Henrietta L. Moore and Todd Sanders. London: Blackwell Publishing.

Pina-Cabral, João de. 2005. "The Future of Social Anthropology." Social Anthropology 13, no. 2: 119-128.

Stafford, Charles. 2008. "Linguistic and Cultural Variables in the Psychology of Numeracy." Journal of the Royal Anthropological Institute 14, no. s1: S128-S141.

Strathern, Marilyn. 2005. Kinship, Law and the Unexpected: Relatives Are Always a Surprise. Cambridge: Cambridge University Press.

Toren, Christina. 2002. "Anthropology as the Whole Science of What It Is to Be Human.” Pp. 105-124 in Anthropology Beyond Culture, ed. Richard Fox and Barbara King. Oxford: Berg.

Viveiros de Castro, Eduardo. 1998. "Cosmological Deixis and Amerindian Perspectivism." Journal of the Royal Anthropological Institute 4, no. 3: 469-488.

Wilson, Richard A. 2004. "The Trouble with Truth: Anthropology's Epistemological Hypochondria." Anthropology Today 20, no. 5: 14-17. 